\section{CITAÇÃO}

Bertolami, O, Gomes, C (2017)

Radiação cósmica de fundo,

Rev. Ciência Elem., V5(03):045.

doi.org/10.24927/rce2017.045

\section{EDITOR}

José Ferreira Gomes,

Universidade do Porto

\section{RECEBIDO EM}

17 de julho de 2017

\section{ACEITE EM}

5 de setembro de 2017

\section{PUBLICADO EM}

30 de setembro de 2017

\section{COPYRIGHT}

(C) Casa das Ciências 2017.

Este artigo é de acesso livre, distribuído sob licença Creative

Commons com a designação CC-BY-NC-SA 4.0, que permite a utilização e a partilha para fins não comerciais, desde que citado o autor e a fonte original do artigo.

\title{
Radiação cósmica de fundo
}

\author{
Orfeu Bertolami ${ }^{\star}$, Cláudio Gomes \\ Departamento de Física e Astronomia, FCUP/ CFP/ Universidade do Porto \\ *orfeu.bertolami@fc.up.pt
}

\begin{abstract}
A Radiação Cósmica de Fundo (RCF) é uma radiação fóssil, observada na região de micro-ondas do espectro eletromagnético, por ser um remanescente do Universo 375 mil anos após o Big Bang e a sua estrutura revela com grande riqueza de detalhes a história do Cosmos ${ }^{1}$.
\end{abstract}

Em 1965, Arno Penzias e Robert Wilson, nos Laboratórios Bell nos EUA, descobriram a RCF através da deteção de um ruído numa radioantena que persistia apesar de uma cuidadosa inspeção do equipamento. Esta radiação foi uma peça-chave na corroboração da teoria do Big Bang, e tem sido estudada por vários satélites espaciais, como o COBE, o WMAP e o Planck, uma vez que é extremamente rica em informação e permite determinar muitas propriedades do Universo e o seu conteúdo. Através da RCF sabemos que a geometria do Universo (este é quadri-dimensional, isto é, tem 3 dimensões espaciais e 1 temporal), correspondente à parte espacial é plana. Esta radiação permite-nos também estimar, com base na teoria da gravitação de Einstein e observações de supernovas distantes, que cerca de $68 \%$ da energia do Universo está distribuída de forma ténue e uniforme por toda a parte, e que por não se manifestar luminosamente, é designada por energia escura, assim como também se consegue inferir que existe mais matéria que a conhecida: a matéria escura.

\section{REFERÊNCIAS}

${ }^{1}$ WEINBERG, S, Os Três Primeiros Minutos (Ed. Gradiva 1987). 